\section{ISEP 2016 ITS for Efficient Energy Use}

The Slovenian ITS Association under the umbrella of the Electro-technical Association of Slovenia organized the 24th International Symposium on Electronics in Transport - ISEP to promote a strategic objective of integrating and strengthening the European Research Area in Slovenia as well as in the other member States, Accession States and in some nearby countries in South Eastern Europe.

The Symposium ISEP 2016 was held on 29-30 March 2016 in Ljubljana, Slovenia, with more than 50 delegates and speakers from 6 countries, with 2 exhibitors and a few journalists. The 2016 topic "ITS for efficient energy use" focused on the importance of support actions and policies for efficient energy use. ITS enables users to make well informed, hence responsible choices on mobility. ITS also improves intermodal transport smoothness. ITS can improve traffic and infrastructure management, hence reduce congestion. ITS can provide tools for a more effective monitoring of environmental performances of vehicles, fleets, supply chains and networks. ISEP 2016 aimed at facilitating co-modality of people and goods, and eco-efficient navigation as well as reducing congestion and supporting traffic management; encouraging (local) authorities to develop a clear mobility policy based on intermodality and new services for intelligent mobility to make better use of the existing energy; sharing practices and identifying opportunities for deployment to reduce $\mathrm{CO} 2$ and associated GHG emissions with the same amount or reduction of energy supply; improve awareness of ITS potential and facilitate the implementation of the best practice.
On the other hand, it is of great importance to establish a research network in Slovenia and nearby countries in the area of ITS and to refer it to the European and regional research.

At the symposium the selected experts and researchers emphasized the importance of ITS, and the need for better design and development of innovative technologies to maximize the use of public transport. Unique to this event is the encouragement of participation by PhD students who are involved in current state-of-the-art transport research and practical issues concerning ITS. The symposium gave PhD students the opportunity to present their PhD work to a knowledgeable audience. At the same time the researchers were given the opportunity to present their achievements. Furthermore, the symposium gave participants from universities, research organisations and industry the opportunity to establish personal contacts with the aim of stimulating an efficient transfer of research results to the market, according to the needs and expectations of the users of all modes of transport.

The aim of the symposium has always been also to encourage the dialogue and cooperation among the participants who are involved in solving transport problems and looking for common ITS solutions. On the other hand, ISEP 2016 was an event with a great opportunity for business and social networking of junior and senior ITS experts, including academia and students.

The second day offered all ISEP 2016 participants the opportunity to visit the Traffic Management Control Centre for the Karavanke tunnel on the border with Austria.

\section{Robert Rijavec, M.Sc. University of Ljubljana Faculty of Civil and Geodetic Engineering}

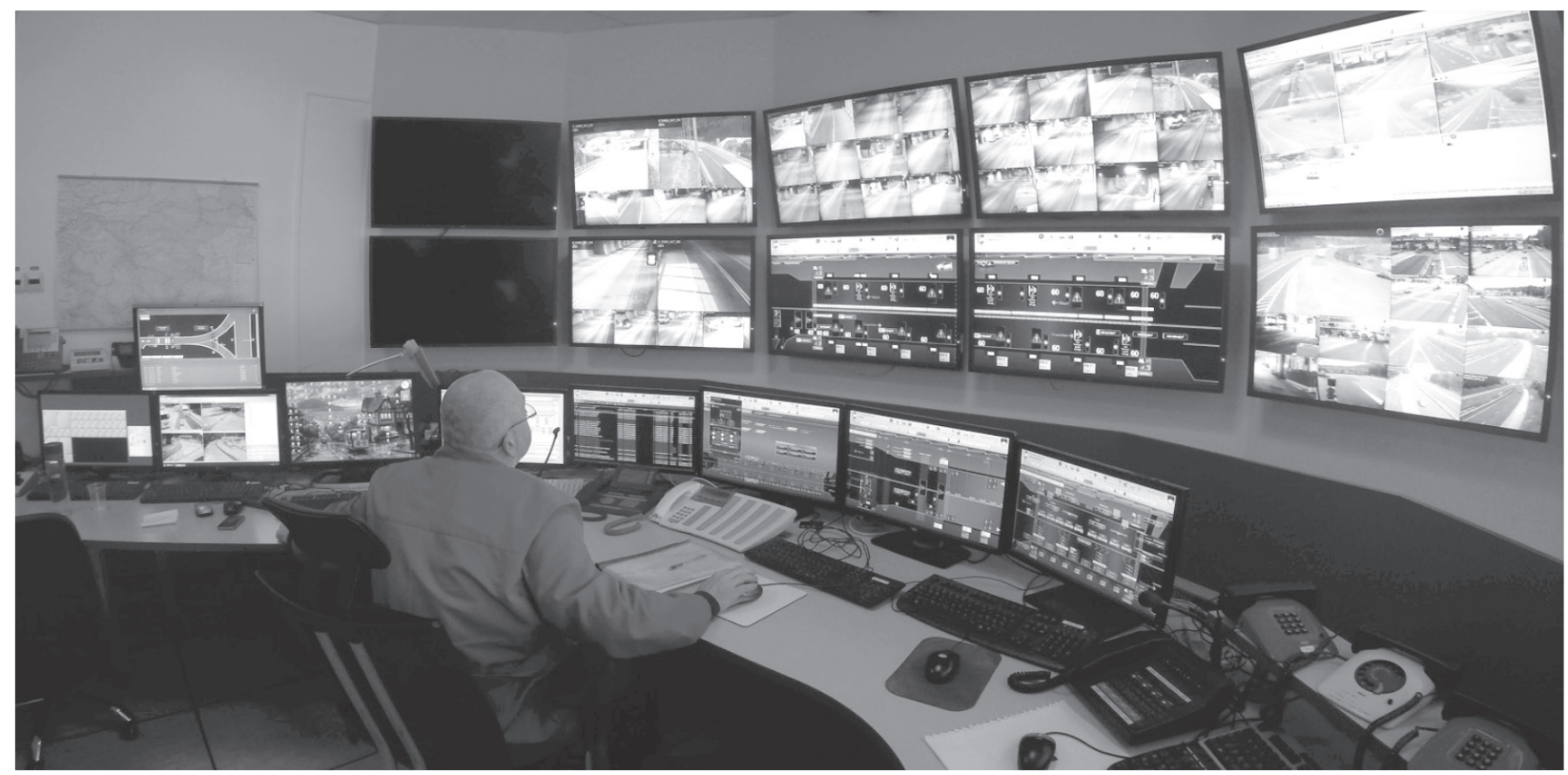

Traffic Management Control Centre for the Karavanke tunnel 